\title{
Corpo, espaço e as políticas do movimento nos filmes de Kelly Reichardt
}

\author{
Cesar de Siqueira Castanha ${ }^{1}$
}

Leslie Marmon Silko (2010), escritora do pueblo de Laguna, começa o texto de suas memórias, o livro The turquoise ledge, descrevendo uma trilha de caminhada, cotidianamente repetida. A trilha tem uma história: os vestígios de uma caminhada pela cordilheira de Tucson, no estado do Arizona, no sudoeste dos Estados Unidos; o rastro das populações indígenas que viviam entre as cordilheiras; as viagens formadas para a escavação de minas; a trilha das formigas e de outros animais que habitam a região. A caminhada é também um processo de adaptação para Silko, dos seus passos sobre o terreno acidentado do deserto, de não permitir que seus pés afundassem na areia às margens do arroio, de sua percepção do que está ao redor no espaço, como descreve a autora:

Lentamente ficou mais fácil, e eu comecei a notar os seixos e pedras na areia branca e fina e os rastros dos animais e sinais de coiote e lince no arroio. Comecei a encontrar pequenas pedras e seixos riscados de turquesa. Ao longo dos anos, eu peguei algumas dessas pedras turquesa, mas eu não estava tão interessada nas pedras como estou agora. Eu precisava de contato quase diário com as pedras turquesa nos meus passeios para desenvolver meu interesse (Silko 2010; tradução nossa²).

O saliente das turquesas, que dá o título das memórias de Silko, torna-se um fenômeno distintivo da sua relação com aquele espaço e de seu movimento por ele, das suas caminhadas, da sua participação naquele ambiente, que compartilha com as trilhas de outros tempos e de outras naturezas, e do seu pertencimento ao País (assim como do que o constitui como país). Na sua experiência afetiva com a região, Silko se apega às narrativas do pueblo, compartilha com elas o espaço

\footnotetext{
1 Universidade Federal de Pernambuco, Av. Prof. Moraes Rego, 1235, Cidade Universitária, Recife, CEP 50670-901, Pernambuco, Brasil.

2 No original: "Slowly it got easier and I started to notice the pebbles and rocks in the fine white sand, and the animal tracks and signs of coyote and bobcat in the arroyo. I began to find small rocks and pebbles streaked with turquoise. Over the years I'd picked up some of these turquoise rocks but I wasn't as interested in the stones as I am now. I needed almost daily contact with the turquoise rocks on my walks to develop my interest".
} 
onde habita - frequentemente, compartilha também da sua própria casa.

Começo este artigo com os movimentos de Silko porque eles nos colocam diante de uma noção histórica, ecológica e diversa de paisagem, de modo mais amplo, e da paisagem estadunidense, de modo mais específico. Tim Ingold (1993, 152), no texto "Temporality of the landscape", adota, para sua consideração ao conceito de paisagem, uma "perspectiva de habitação", em que ela seria constituída "como um registro duradouro de - e testemunho para - as vidas e os trabalhos de gerações passadas que a habitaram e, ao fazêlo, deixaram ali algo de si mesmos", ou seja, de uma temporalidade definida pelo autor como uma tarefagem, compreendida aqui como a matriz de atividades relacionadas e o espaço construído (e sempre em construção) da atividade humana. Ingold (1993, 152) também acentua que, para se adotar uma perspectiva desse tipo, é necessário "privilegiar os entendimentos de que pessoas derivam de seu envolvimento cotidiano e vivido no mundo".

Ingold entende a paisagem como uma continuidade das operações de trabalho ou habitação na terra, como um gênero da antropologia, arqueologia, geografia e ecologia. Em um texto mais recente, Ingold (2015) menciona o entendimento de James Gibson, para quem "o ser vivo está posicionado não na superfície exterior de um globo sólido, como Immanuel Kant havia imaginado, mas sim no centro de um campo esférico, compreendendo os dois hemisférios do céu e da Terra". Com Ingold, então, estamos lidando com uma ontologia da habitação, da participação no mundo, tanto quanto da paisagem - ou melhor, estamos lidando com a paisagem como esse resultado de uma integração ao mundo. Por esse motivo, pode ser importante trazer à consideração o entendimento de Ingold (1993), para quem a paisagem não é "nem idêntica à natureza, nem está do lado da humanidade contra a natureza", estabelecendo que:

Como o domínio familiar da nossa habitação, [a paisagem] está conosco, e não contra nós, mas ela não é menos real por isso. E por vivermos nela, a paisagem se torna uma parte de nós mesmos, assim como nós somos parte dela. Além do mais, o que serve para seus componentes humanos serve para seus outros componentes também. Em um mundo construído como natureza, cada objeto é uma entidade autocontida, interagindo com outros através de algum tipo de contato externo. Mas, em uma paisagem, cada componente envolve dentro de sua essência a totalidade das suas relações com todos os outros (Ingold 1993, 154; tradução nossa ${ }^{3}$ ).

\footnotetext{
${ }^{3}$ No original: "As the familiar domain of our dwelling, it is with us, not against us, but it is no less real for that. And through living in it, the landscape becomes a part of us, just as we are a part of it. Moreover, what goes for its human component goes for other components as well. In a world construed as nature, every object is a selfcontained entity, interacting with others through some kind of external contact. But in a landscape, each component enfolds within its essence the totality of its relations with each and every other".
} 
O autor também cita a noção de Peter Gould e Rodney White, para quem, nas palavras de Ingold (1993, 155), "somos todos cartógrafos em nossas vidas cotidianas" e "usamos nossos corpos como um agrimensor usa seus instrumentos, para registrar uma absorção sensória de múltiplos pontos de observação”. Essa relação entre o corpo e o espaço é mais diretamente abordada, no entanto, por Elizabeth Grosz. No texto "Bodies-Cities”, Grosz se diz interessada justamente em uma agência do corpo sobre o espaço e vice-versa. Nas suas palavras, ela buscaria "explorar as maneiras em que o corpo é [...] discursivamente ou representacionalmente produzido e as maneiras em que, em seu lugar, os corpos se reinscrevem ou se projetam no ambiente sociocultural" (Grosz 1992, 242). Para Grosz (1992), a complexidade dessas relações de introjeções e projeções impede que tanto o corpo quanto o ambiente produzam um ecossistema organicamente unificado.

A paisagem, como a trilha cotidiana de Silko, é assim atravessada por essa interação com o corpo. E este, por sua vez, apresenta-se marcado pelo espaço. Grosz $(1992,242)$ se refere a essa ingerência por "modos de simulação", que teriam "tomado e transformado qualquer realidade que cada qual poderia ter tido na imagem do outro: a cidade é feita e refeita no simulacro do corpo; e o corpo, por sua vez, é transformado, citificado, urbanizado como um corpo distintamente metropolitano". A escolha pela cidade como o espaço utilizado para o contraponto que a autora estabelece com o corpo não deve ser tomada no sentido de uma especificidade urbana dessa relação tensiva, no que, para Grosz (1992, 242-243), "a cidade se tornou o termo definidor na construção da imagem da terra e da paisagem". Nas palavras da autora:

A cidade fornece a ordem e a organização que vinculam automaticamente os corpos que, de outra forma, não estão relacionados. Por exemplo, ela liga o estilo de vida afluente do banqueiro ou profissional à miséria do mendigo, dos sem-tetos ou dos pobres, sem necessariamente postular uma vontade de exploração consciente ou intencional. É a condição e o meio em que a corporeidade é socialmente, sexualmente e discursivamente produzida (Grosz 1992, 243; tradução nossa ${ }^{4}$ ).

Em um texto como o de Silko (2010), a paisagem aparece a partir de um movimento do corpo: os percursos da autora e o reconhecimento de outras caminhadas. Além disso, a autora frequentemente se coloca como dispondo do seu corpo para uma ação do espaço através dele. Isso se dá mais marcadamente na terceira parte do livro, intitulada "Star-beings". Nesse ponto, Silko descreve sua dedicação aos seres das estrelas (tomando essas figuras de

\footnotetext{
${ }^{4}$ No original: "The city provides the order and organization that automatically links otherwise unrelated bodies. For example, it links the affluent lifestyle of the banker or professional to the squalor of the vagrant, the homeless, or the impoverished without necessarily positing a conscious or intentional will-to-exploit. It is the condition and milieu in which corporeality is socially, sexually, and discursively produced".
} 
narrativas ancestrais de etnias indígenas na América e na Austrália), que exigem dela a pintura de seus retratos. Esse processo atende não apenas ao hibridismo entre corpo-cidade previsto por Grosz, mas também, e aqui destaco especialmente, à vinculação entre paisagem e temporalidade a partir de um processo definido por Ingold (1993, 158) como tarefagem - esta que é representativa do conjunto conectado de "padrões de atividades de habitação". Entende-se, dessa maneira, que é no próprio processo de habitação que se constituem as formas da paisagem. Para Ingold (1993), a paisagem seria então a forma solidificada do processo de tarefagem. A representação do espaço (seja no gesto de pintar os retratos dos seres das estrelas ou de buscar essa representação a partir de uma produção textual ou audiovisual), portanto, é uma que dá forma ao processo contínuo de tarefagem, que, até então, teriam suas próprias formas suspensas no movimento. Em outras palavras, é no agenciamento formal dos padrões, práticas e temporalidades da tarefagem que se constituem tanto as representações do espaço quanto aquilo que chamamos de paisagem.

Para Ingold (1993, 162), isso se daria porque "a paisagem assume suas formas em um processo de incorporação, não de inscrição", o que se contrapõe às noções de paisagem como um marco de distanciamento e perda de lugar do sujeito com a terra (como na descrição do fenômeno por Jean-Luc Nancy ${ }^{5}$ ) ou do seu entendimento como um gênero que se dá em um aparecimento autônomo, livre de eventos ${ }^{6}$, do espaço. Como incorporação, nesse sentido, "as formas da paisagem surgem em conjunto com as da tarefagem”, esta que deve ser ocupada por seres que agem no seu próprio processo de habitação - uma tarefagem, deste modo, que existe não apenas como atividade, mas como interatividade (Ingold 1993, 162). Parto desse princípio de Ingold para um reconhecimento da paisagem a partir desses processos de incorporação nos filmes Wendy e Lucy (Wendy and Lucy, 2008) e O atalho (Meek's Cutoff, 2010). Estabelecer essa noção ampliada de paisagem é necessário no que aqui se pretende analisar a apresentação do fenômeno nos filmes dirigidos pela cineasta estadunidense Kelly Reichardt. Paisagem, nesses filmes, torna-se um conceito problemático no que o espaço não se distingue dos corpos dos personagens, de sua relação vivida com o ambiente que os cerca.

\footnotetext{
${ }^{5}$ Refiro-me à distinção proposta por Jean-Luc Nancy (2005), no ensaio "Uncanny landscape", em que, ao distinguir a paisagem, Nancy faz uma referência à emancipação desta como aquilo que não é o país, ou o lugar de que o camponês não se sente parte, a que ele não pertence.

${ }^{6}$ No ensaio "Entre cenário e paisagem no cinema", Martin Lefebvre (2006) evoca a história da paisagem e do seu surgimento como motivo nas artes plásticas, partindo de uma diferenciação entre cenário e paisagem. Ele menciona o trabalho da historiadora da arte Anne Cauquelin. Esta observa a ausência da noção e do termo paisagem na Grécia Antiga, colocando, como contraponto, uma noção de cenário. O cenário, segundo Cauquelin (1989 apud Lefebvre 2006), é onde a ação acontece, e nenhuma representação narrativa pode ser feita sem ele. Quanto ao que diferencia cenário de paisagem, M. Lefebvre utiliza, como ponto de partida, o princípio de Cauquelin de que, nas artes visuais, paisagem é espaço livre de eventos.
} 
Em Wendy e Lucy, Wendy Carroll (Williams), desempregada e viajando para buscar trabalho no Alasca, tem um problema com o carro quando está de passagem em uma pequena cidade no estado de Oregon. Sem habitação e com pouco dinheiro, a personagem participa daquele espaço e habita a sua precariedade. Em $O$ atalho, um grupo de colonos, guiado por Stephen Meek (Bruce Greenwood), busca um espaço onde possa se estabelecer ao atravessar a trilha de Oregon. Meek, no entanto, toma um atalho inadequado, afastando os viajantes da trilha. Perdidos, os personagens se dedicam a buscar alguma fonte de água para que possam dar continuidade à viagem.

A paisagem aqui não é autônoma, mas o produto de interações históricas e da diversidade da habitação humana em um dado espaço. Como em Silko, a paisagem do cinema de Reichardt se dá em uma trilha por sobre outras caminhadas, em uma travessia pelo espaço comum. O cinema de Kelly Reichardt, no que está sempre apresentando os espaços da paisagem estadunidense a partir de como seus personagens interagem com ela e da presença de seus corpos nos espaços que ocupam, aparece como um conjunto fílmico especialmente interessante para se considerar esse problema. Reichardt nos permite, como Silko, a falar em termos de uma travessia ${ }^{7}$, ou um "transe de caminhada", atravessar o espaço como um processo de repetição do trabalho, e especialmente do trabalho feminino ${ }^{8}$, como ela mesmo se refere a $O$ atalho em entrevista (em Gilbey 2011). Como esses filmes levam adiante o vínculo das formas da paisagem com as formas da tarefagem e essa relação de ingerência entre os espaços externos e os processos do corpo? E, de modo geral, como a materialidade dos filmes apresenta esse dado entendimento da ideia de paisagem a partir do percurso dos corpos pelo espaço fílmico?

\section{Corpo, espaço e imobilidade}

Em um livro sobre a filmografia de Reichardt, ao abrir o capítulo "Precariedade: Wendy e Lucy", as autoras Katherine Fusco e Nicole Seymour citam uma fala do diretor Todd Haynes, que descreve os filmes da cineasta como "espécies de road movies ${ }^{9}$ fracassados" (em Hornaday 2011 apud Fusco e Seymour 2017). Haynes então se refere aos filmes River of grass (1994), Antiga alegria (Old Joy, 2006), Wendy e Lucy (Wendy and Lucy, 2008) e O atalho (Meek's Cutoff, 2010). Falemos um pouco, brevemente, desses dois primeiros filmes, o que faz deles road movies fracassados, da carreira de Reichardt até Wendy

\footnotetext{
${ }^{7}$ Descrevendo sua prática como professora de cinema, Reichardt (em Dillard 2016) chama atenção para a importância de um movimento dos personagens pelo quadro, como um gesto que faz da decupagem no cinema algo além de uma ferramenta para se acompanhar os diálogos.

8 Em uma entrevista ao The guardian sobre $O$ atalho, Reichardt disse estar interessada em "uma visão diferente do Oeste da série usual de encontros masculinos e batalhas de força e apresentar essa ideia de ir para o Oeste como apenas um transe de caminhada" (em Gilbey 2011).

${ }^{9}$ Gênero cinematográfico referente aos filmes de viagem, também conhecido como "filme de estrada".
} 
e Lucy e por que, a essa altura, isso já era reconhecido como uma recorrência de sua filmografia.

Kelly Reichardt é definida por Fusco e Seymour (2017) como uma cineasta independente estadunidense. $O$ primeiro longametragem dirigido por ela é River of grass, de 1994, ambientado na Flórida, seu estado natal. River of grass apresenta um jovem casal que pretende fugir ao entender (erroneamente) que matou uma pessoa ao disparar uma arma por acidente. Nesse sentido, o filme pode funcionar até mesmo como uma sátira de Bonnie e Clyde (Bonnie and Clyde, 1967), uma que substitui os dois notórios ladrões de banco por uma autoidentificação equivocada com essa vida de crime e fuga - os personagens de River of grass, afinal, não cometeram nenhum crime, nem ninguém os persegue. O próprio pôster do filme brinca com esse imaginário, apresentando o slogan "Uma garota, uma arma e nenhum lugar para onde ir". Mas a sátira entra em operação uma vez que os personagens, na verdade, nunca conseguem sair do estado da Flórida. Esse desejo de habitar a estrada termina, por fim, absolutamente frustrado. Depois de River of grass, Reichardt não conseguiu financiar seu segundo projeto, The royal court, "virtualmente desaparecendo da cena independente pelos próximos 12 anos" (Fusco e Seymour 2017). Ela voltou a dirigir longas-metragens com o filme Antiga alegria, em 2006.

A partir de Antiga alegria, o cinema de Kelly Reichardt vai se definir por outras recorrências: uma estética mais próxima do realismo, uma relação mais direta com o contexto socioeconômico e histórico do país e uma temporalidade mais dilatada. No filme, dois amigos adultos se reúnem e viajam para acampar em uma região próxima. Um desses amigos (Mark, interpretado por Daniel London) foi assimilado à vida familiar de classe média no subúrbio. $\mathrm{O}$ outro (Kurt, interpretado por Will Odham) mantém uma vida mais instável e errante, não está casado e nem tem um emprego fixo. O filme se passa nos últimos anos do governo Bush nos EUA, um cenário que Reichardt, a diretora e corroteirista do filme (o texto é também de Jonathan Raymond), apresenta mais diretamente pela inserção de trechos dos programas da Air America, uma emissora de rádio liberal, focada numa programação de debates, entrevistas e noticiários, que durou de 2004 a 2010.

O programa na rádio também funciona como um comentário à experiência de classe média liberal que envolve os dois personagens, e a viagem em si. Em um dado momento, logo que Mark busca Kurt, ouvimos da programação a opinião de que os democratas acham que é mais relevante fazer parte do governo do que "se juntar ao povo". Afirma, ao rádio, uma voz masculina: "A oportunidade não está só batendo na porta, está esmurrando a porta. E lá está o burro democrata, sentado e tomando chá dizendo: 'Eu não sei! Eu não sei se deveria levantar para atender a porta ou não’”. É fácil perceber como essa condição, de um discurso crítico que não se mobiliza para fora de uma condição de letargia e precariedade, perpassa a experiência política dos personagens e até a iniciativa do programa em si. 
A imobilidade e a ideia de um road movie fracassado, a que Haynes se refere, começa então a se delinear, no cinema de Reichardt, como um reconhecimento de atividade ou falta de atividade política, no sentido em que os personagens são agentes de um contexto político de desigualdade e precariedade econômica. Pensar em Wendy e Lucy a partir dessa chave do road movie fracassado pode ser, portanto, especialmente interessante quando consideramos que, de todos os longas-metragens de Reichardt, é este que se pauta mais estritamente por uma experiência de imobilidade. Wendy Carroll (interpretada por Michelle Williams na primeira de suas três colaborações com a cineasta) está, afinal, impedida de se mover para fora da pequena cidade no Oregon em que seu carro parou (aparentemente, de vez) e em direção ao Alasca, onde pretende encontrar um emprego.

Quando Wendy primeiro chega à cidade (e mais tarde, quando está procurando Lucy, sua cachorra de estimação), deparamo-nos com cargas de trem paradas sobre os trilhos. O movimento impedido parece ser algo que toma a experiência da cidade como um todo, no que percebemos a repetição de padrões cotidianos nas operações de trabalho (outro personagem de maior destaque do filme, um segurança de meia idade que age em auxílio de Wendy, passa seus dias parado em um mesmo ponto da paisagem) e uma cartografia estritamente limitada (cada caminhada de Wendy pela cidade é mapeada de alguma maneira, com restrições de horários, trajetos ou espaços onde estacionar seu carro). E o contexto da cidade ainda é interligado ao da personagem, uma vez que é necessário Wendy traçar repetidos percursos pelas proximidades para procurar a sua cachorra Lucy, que desaparece quando sua tutora é levada à delegacia por tentativa de furto em um supermercado.

O que permanece, no filme, é a cidade que contém a experiência dos personagens, apresentada por contextos históricos de desesperança, precariedade e austeridade. Nessa perspectiva, mesmo que a jornada de Wendy se vincule formalmente aos transes de caminhada de Reichardt e ao seus road movies fracassados, ela é apresentada por uma fixidez característica. Essa contradição é entendida como uma ironia em Fusco e Seymour, no que as autoras colocam:

Também podemos reconhecer ironia dramática no mantra da nossa protagonista, proferido em diversas variações durante o filme: 'Eu não sou daqui - só estou de passagem'. Em um sentido, esta fala é tragicamente irônica, na medida em que vimos Wendy falhar repetidas vezes, dia após dia, para 'passar' desta pequena cidade e alcançar o seu objetivo do Alasca [...] Mas o mantra de Wendy é irônico em outro sentido: até onde vai o enredo e nossa relação como espectadores com Wendy, ela, de fato, se não é 'daqui', simplesmente está 'aqui'. Isso é, nós a vemos operar em um contexto apenas, aquele de uma pequena cidade do Oregon onde toda a ação do filme tem lugar, sem flashbacks e sem planos que nos estabeleçam em um 
tempo ou lugar anterior, sem epílogo de 'seis meses depois' (Fusco e Seymour 2017; tradução nossa ${ }^{10}$ ).

O percurso do corpo de Wendy pelo espaço fílmico não é, assim, uma iniciativa prazerosa da personagem. A sua caminhada não é o fenômeno de "apropriação do sistema topográfico pelo pedestre" que Michel de Certeau $(1998,177)$ descreve em $A$ invenção do cotidiano. O caminhar, em Wendy e Lucy, é lido de forma mais adequada como "uma rede de percursos errático-simbólicos que atravessam e descrevem o espaço" (Careri 2013, 44) - um entendimento que se materializa na forma literária de Silko e que, em Reichardt, nos permite reconhecer os processos de formação da paisagem a partir da tarefagem mesmo nos percursos restritos de Wendy. Como, então, o espaço é encenado e incorporado a partir desses percursos?

No seu entendimento do conceito de cidade, Grosz $(1992,244)$ a define como "uma rede complexa e interativa, que une [...] atividades sociais, processos e relações díspares com um número de relações públicas, cívicas, geográficas, projetadas ou arquitetônicas, reais ou imaginárias”. A permanência de Wendy, a sua imobilidade, coloca-nos diante dos processos socioeconômicos daquele espaço; diante não só de um quadro contextual da paisagem americana da recessão, mas de um ritmo, de uma paisagem que apresenta a materialidade mesma dessa austeridade. Dito de outra maneira, a repetição dos percursos de Wendy revela os processos da cidade, como reconhecidos por Grosz $(1992,244)$ - "as redes de poder, as formas de deslocamento, gerência e organização políticas, relações sociais interpessoais, familiares e extra-familiares e uma organização estético-econômica do espaço e lugar" que a cidade junta para "criar um semi-permanente, mas em constante mudança, ambiente ou meio construído" -, na sua materialidade fílmica.

Há, nesse sentido, uma integração dos processos fílmicos aos processos paisagísticos daquele espaço. Quando Wendy se aproxima do seu carro à noite no silêncio e quase completa escuridão, temos o quadro fílmico iluminado diegeticamente por um único poste de luz. Quando a personagem é despertada, em seu carro, pelo segurança, avisando-a de que não poderia estacionar na calçada de uma propriedade privada - levando-a então a empurrar seu carro para a calçada pública -, logo os modos de ocupação da cidade são ordenadamente distribuídos. A atribuição da propriedade a uma figura ausente também é especialmente interessante, no que nos deparamos com uma série de ruas vazias e estabelecimentos fechados

\footnotetext{
${ }^{10}$ No original: "We might also recognize dramatic irony in our protagonist's mantra, uttered in several variations throughout the film: 'I'm not from here - I'm just passing through.' In one sense, this statement is tragically ironic, insofar as we've seen Wendy fail over and over, day by day, to 'pass through' this small town and reach her goal of Alasca [...] But Wendy's mantra is ironic in another sense: as far as the plotline goes, and as far as our viewing relationship with Wendy goes, she actually is, if not 'from here,' simply here. That is, we see her operate in one context only, that of the small Oregon town where all the film's action takes place".
} 
como um espaço onde se movimentam trabalhadores, mendigos e pessoas desabitadas. Entre a gerência de uma macropolítica (a recessão e o desemprego) e a dinâmica específica do lugar, apresentase a cidade, o "meio do caminho entre a vila e o Estado, compartilhando das interrelações interpessoais da vila (numa escala de vizinhança) e do âmbito administrativo do Estado" (Grosz 1992, 244).

A cidade é apresentada em Wendy e Lucy como um contraponto à expectativa de Wendy de encontrar emprego e oportunidade em um lugar novo, porque, neste lugar novo, que deveria ser/constituir um ponto no caminho de Wendy para a superação da sua condição de precariedade, o espaço fílmico da cidade não dá nenhuma indicação de que essa superação está próxima. Pelo contrário, como reconhecem Fusco e Seymour (2017), "a desolação dos seus arredores sugere uma falta de oportunidade de emprego local”. Em sua leitura, Fusco e Seymour $(2017,40)$ entendem a personagem como se espelhando na estagnação daquele ambiente, identificando-a dentro da imobilidade de uma "recentemente precária classe trabalhadora branca", concluindo assim que Wendy "não pode deixar o lugar que não tem nada a oferecer a ela - assim transtornando ideologias de avanço libertador e de sonhos estadunidenses".

Seguiremos também esse entendimento no que a situação particular de Wendy sustenta um aspecto de despossessão, o que a própria diretora (em Fusco e Seymour 2017) relaciona a um contexto geral de despossessão causado pelo furacão Katrina, que é definido por Cornel West (2005 apud Levitt e Whitaker 2009), no The observer, como "a mais nua manifestação de política social para os pobres, em que a mensagem tem sido, por décadas: 'Vocês estão por conta própria'”. Para Fusco e Seymour (2007), a branquitude de Wendy a distingue, no entanto, desse mesmo contexto - tendo sido a população negra uma das maiores vítimas do Katrina. As autoras leem, desse modo, a branquitude da personagem como um reconhecimento correlacionado a diversas especificidades socioeconômicas e políticas dos EUA contemporâneo (a precariedade recente da classe trabalhadora branca relacionada à recessão, a exaustão de um movimento demasiado branco da nova esquerda e a cooptação dos trabalhadores brancos pelo partido republicano). O processo de se dar conta dessa experiência de despossessão se torna, então, um dos percursos de Wendy, no que sua viagem é interrompida para além de seus planos.

Em Dispossession: the performative in the political, Judith Butler (2013) define despossessão em dois aspectos: a nossa dependência a poderes que nos sustentam e nos privam; e a despossessão de nossos direitos, terras e modos de pertencimento. Para chegarmos a esta experiência de despossessão, necessariamente passamos pela experiência anterior. Nas palavras da autora (2013, 4-5), "somos seres interdependentes, cujo prazer e sofrimento dependem desde o início de um ambiente que sustenta e um mundo social sustentado"; desse modo, "só podemos ser despossuídos porque já estamos 
despossuídos", no sentido de que "nossa interdependência estabelece nossa vulnerabilidade a formas sociais de privação".

Wendy e Lucy encena essa experiência de despossessão em um contexto em que há um risco maior colocado a corpos não brancos do que a corpos brancos e então reconhece, ainda dentro desse contexto de precariedade, a branquitude de Wendy. A situação de precariedade em que esse corpo se encontra é então correlacionada a uma experiência de branquitude. $\mathrm{O}$ aspecto de precariedade que define a relação hesitante entre mobilidade e imobilidade do corpo de Wendy se confunde, assim, com a letargia encenada pelos corpos brancos de Antiga alegria. Em $O$ atalho, o movimento desse corpo branco desabitado volta, mais uma vez, para uma confluência entre o contexto de precariedade (a sede e o cansaço dos colonos) e letargia (a incapacidade de agir politicamente sobre aquele espaço). A letargia é incorporada e colocada em cena também no sentido em que Wendy - assim como os amigos de Antiga alegria e, até certo ponto do filme, todos os personagens brancos de $O$ atalho - parece não estar plenamente consciente do contexto de despossessão em que está inserida (ou até deliberadamente o ignora).

A partir de Antiga alegria essa letargia também é trazida aos filmes de Reichardt em uma forma fílmica da austeridade - um realismo silencioso, que se sustenta na manutenção de uma observação indiferenciada. Além disso, o fracasso de uma promessa econômica para esses corpos brancos, baseada em uma expectativa de fartura $^{11}$, produz imagens que se repetem por todo o cinema de Reichardt. São imagens de fábricas, fragmentos encontrados de indústrias falidas (no sentido financeiro ou moral), de um sistema que já não sustenta uma crença entre seus habitantes, mesmo à população branca, a quem essa promessa foi construída para privilegiar ${ }^{12}$. Ao percorrerem uma zona industrial agora incapaz de cumprir sua promessa de emprego, renda e suporte, os personagens de Reichardt

\footnotetext{
${ }^{11}$ Algo que está presente em uma representação hegemônica e discursos sobre o país desde o período colonial, como nos mostra Leo Marx (2000) em seu The machine in the garden, e que permanece até hoje, como aqui nos descreve o autor (2000): "Quanto à noção subordinada do novo continente como uma terra de abundância, isso é, como sabemos, agora mais forte do que nunca. Hoje alguns historiadores acentuam o que o viajante do século XVI chamou de 'incrível fartura' como talvez a mais importante distinção característica da vida americana. No nosso tempo, certamente, a ideia é menos rigorosamente associada com a paisagem que com a ciência e tecnologia".

12 Aníbal Quijano $(2005,132)$, no texto "Colonialidade do Poder", nos diz que configuração histórica dos EUA como Estado-nação era "genuinamente representativa" da maioria da população, desde que seja reconhecida, no entanto, a branquitude social que constitui esse Estado-nação. Isso se dá, em parte, porque os territórios indígenas invandidos foram apropriados e distribuídos tanto em uma concentração de grandes latifúndios quanto em "uma vasta proporção de médias e pequenas propriedades", o que seria "equivalente, pois, a uma distribuição democrática de recursos". Conclui Quijano (2005, 132): "Isso fundou para os brancos uma participação notavelmente democrática no controle da geração e da gestão da autoridade pública. A colonialidade do novo padrão de poder não foi anulada, no entanto, já que negros e índios não podiam ter lugar, em absoluto, no controle dos recursos de produção, nem das instituições e mecanismos da autoridade pública".
} 
performam uma relação de ingênuo desapontamento com os espaços que os recebem - como Wendy ao caminhar por uma cidade incapaz de lhe oferecer qualquer ajuda e os personagens de Antiga alegria, que se satisfazem com as críticas conduzidas por uma rádio liberal. Diante de uma hostilidade desses espaços - ou, mais do que isso, de uma incapacidade deles de oferecer qualquer mudança à situação de precariedade dos personagens -, mesmo o movimento no cinema de Reichardt é marcado por uma rigorosa sensação de imobilidade na relação que é estabelecida com as contradições da paisagem estadunidense.
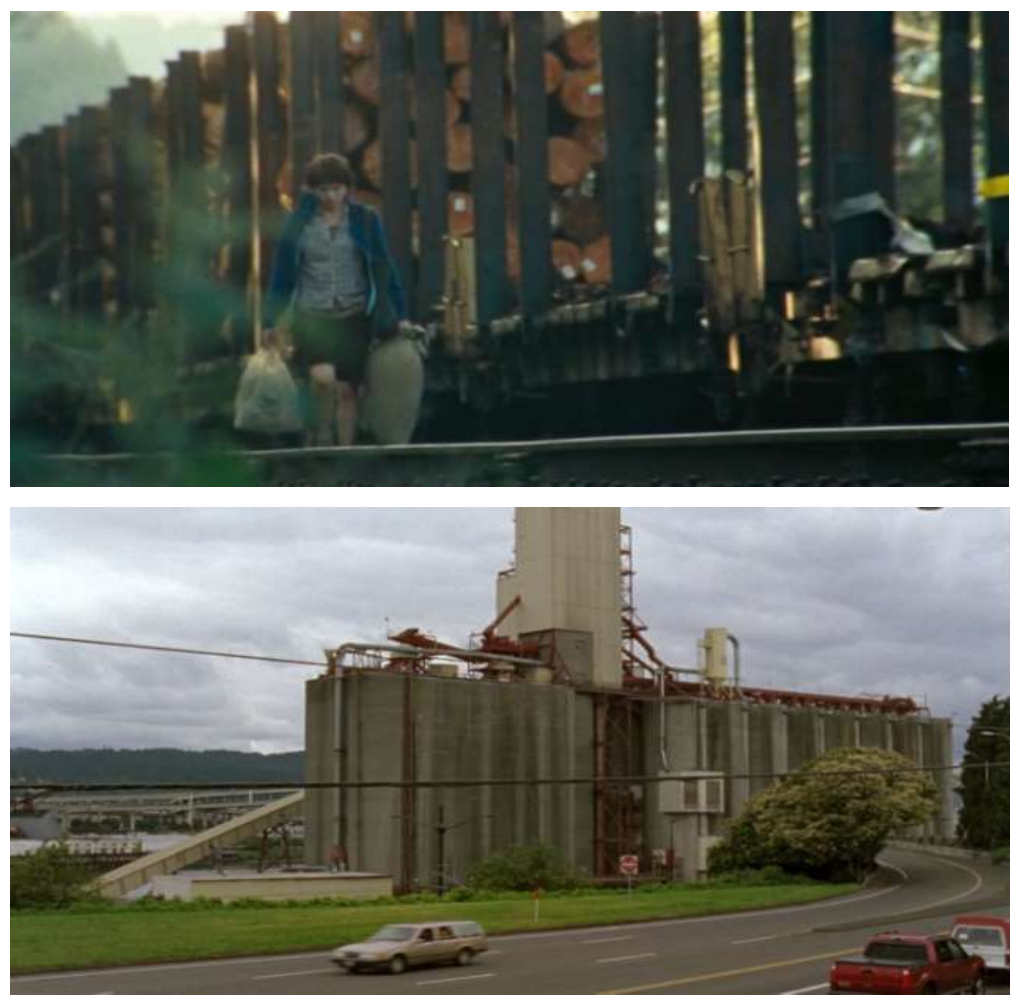

Figuras 1 e 2: Cena dos filmes Wendy e Lucy (à esquerda) e Antiga alegria (à direita) (C) Film Science, Washington Square Films et al.

Ainda assim, apesar do caráter circunscrito, limitado e letárgico desse percurso, os corpos dos filmes de Kelly Reichardt estão em constante movimento por essa paisagem estadunidense contemporânea. A forma fílmica de Reichardt, além do mais, faz uso específico desse movimento na encenação do espaço, na construção da temporalidade, no trabalho sonoro e na concepção de uma estrutura narrativa desses filmes. Partindo inicialmente do filme $O$ atalho, consideremos como essa forma fílmica do movimento se materializa nos corpos cansados, desabitados e letárgicos dos personagens de Reichardt.

\section{Corpo, espaço e movimento}


Consideremos aqui $O$ atalho por duas encenações: uma dos viajantes e seu prisioneiro, o corpo cansado de cada um caminhando pelo deserto com sede, as operações de trabalho que se repetem; a outra, do espaço que atravessam, a materialidade da natureza seca desse deserto, a presença incontornável da luz do sol e a escuridão das cenas noturnas. É na travessia desse corpo por esse espaço que se constrói $O$ atalho, um filme que trata, afinal, de uma angústia muito ambígua do desejo por dar início à habitação de um espaço já habitado, por se fazer presente em um espaço já tão cheio de presenças. A impossibilidade de os colonos, em $O$ atalho, habitarem o deserto americano por onde caminham, ou mesmo a relação tensiva que se estabelece entre eles e esse espaço, apresenta-se, na materialidade fílmica, como o reconhecimento de um contexto de precariedade a partir do modo como essa paisagem é encenada.

Mesmo em um primeiro momento do filme, quando vemos os personagens mergulharem em um rio, lavando-se com a sua água e trazendo o gado até ela, antes de se perderem e enfrentarem a sede, a sequência não se define por uma experiência de habitação. O que toma a frente no enquadramento de Reichardt é o espaço natural - as pequenas piscinas que se formam na correnteza mais seca do rio, a vegetação das margens. Uma vez que os personagens começam a se afastar desse espaço, temos um enquadramento que se fecha em um pedaço do rio atravessando a terra. Não há presença humana, ouvimos apenas o som da correnteza, como parte daquela paisagem. É à medida que os personagens vão se afastando da água doce que eles vão tomando parte do quadro por meio de um fade, e o som das águas vai, aos poucos, deixando de fazer parte daquela paisagem. Afastar-se do som da correnteza implica também, no filme, em uma imersão no repetitivo som das rodas das carroças sobre a terra seca. A ausência do som da correnteza está sempre relacionada ao transe martirizado da repetição do som das rodas.

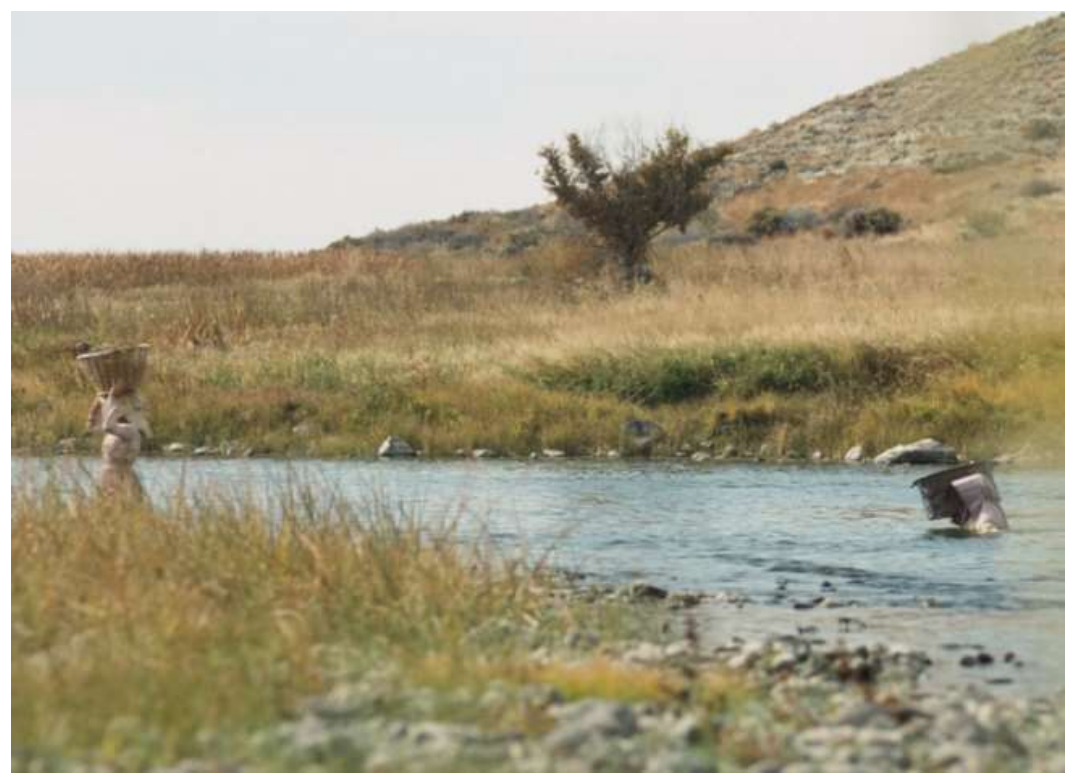


Figura 3: Cena do filme $O$ atalho (2010) | (c) Film Science et al.

No percurso, a repetição do espaço é materializada em uma repetição dos movimentos. O som constante da madeira das carruagens por sobre o solo do deserto ${ }^{13}$ e a caminhada tomam, de fato, boa parte do filme, mas um outro movimento que se repete, enquanto o corpo dos personagens é progressivamente debilitado pelas condições da jornada, é aquele das suas operações incorporadas de trabalho. A contradição posta em cena em $O$ atalho é que a inabilidade dos colonos de transformar aquele espaço a partir de seu esforço individual (uma inabilidade que se assemelha à letargia de Antiga alegria e Wendy e Lucy) é experimentada por corpos que estão constante e ininterruptamente agindo sobre esse espaço, seja pelo trabalho ou pela caminhada.

A construção de cena de $O$ atalho é montada a partir dessa relação entre caminhada e trabalho, ou melhor, da caminhada como trabalho. Nesse sentido, o filme se alia especificamente à perspectiva das personagens mulheres e das operações incorporadas, por elas, de trabalho feminino. $\mathrm{O}$ quadro se move junto com as personagens e se fixa quando elas param para montar acampamento provisório, cozinhar e até permanecerem paradas em silêncio para ouvir a leitura da Bíblia - um gesto que o filme também dá conta como uma dessas operações contínuas de trabalho feminino. Em entrevista, Reichardt justifica a escolha por uma janela de 1.33:1 para o filme também como um modo de replicar a perspectiva limitada das personagens e a experiência de imediatismo com o espaço proporcionada pelos grandes gorros que levam na cabeça, em que "você não vê o amanhã ou o ontem no plano" (Longworth 2011).

Esse investimento formal em uma reencenação da experiência de movimento das personagens cria, na construção de cena do filme, aquilo que pode levá-lo a ser lido como parte de um cinema da lentidão ${ }^{14}$. É verdade, no entanto, que Reichardt não se engaja no mesmo processo de dilatação temporal da cena que outros cineastas

\footnotetext{
${ }^{13}$ A permanência desse som por quase toda a jornada tem um aspecto de reiteração do martírio, do transe de caminhada que caracteriza o movimento dos personagens. Não seria estranho entender esse tipo de sonoridade dessa forma, no que o percurso das carruagens por sobre os paralelepípedos, produzindo um som prevalecente em determinadas paisagens sonoras, chegou a ser proibido, segundo R. Murray Schafer (1994), em lugares como a Cidade do Cabo (África do Sul) e Adelaide (Austrália). Em outro momento, o autor (1994) cita uma descrição do som como "infernal". Embora Schafer se refira mais especificamente aos sons da carruagem no espaço urbano, mesmo quando o autor se volta para um reconhecimento da diferença entre a carruagem que circula sobre o paralelepípedo e a que atravessa o solo aberto, o som desta última é definido no arquivo do autor (1994) como "hipnótico", o que reitera, mais uma vez, o aspecto de transe produzido pela repetição e invariabilidade da caminhada.

${ }^{14}$ Em um livro que reconhece a recorrência dessa estética da lentidão no cinema contemporâneo, os autores Tiago de Luca e Nuno Barradas Jorge (2016) creditam a expressão "slow cinema" ao crítico Michel Ciment e à posterior análise de Matthew Flanagan (2008 apud Luca e Jorge 2016), que define a estética por seus planos longos, narrativas descentralizadas e ênfase no cotidiano.
} 
contemporâneos mais frequentemente reconhecidos dentro da estética da lentidão, como Tsai Ming-Liang, Béla Tarr, Lav Diaz, Lisandro Alonso e Carlos Reygadas. Seus planos são, geralmente, mais curtos que os destes cineastas; e os procedimentos de uma narrativa estão, em seus filmes, mais presentes. Mas a aproximação de Reichardt a essa estética é reivindicada na sua tentativa de fidelidade a uma materialidade da experiência do percurso.

Se as chaves da lentidão e da temporalidade dilatada são insuficientes para uma leitura específica ao cinema de Kelly Reichardt (que não recorre à temporalidade de outras obras do chamado slow cinema), penso aqui, no lugar disso, um agenciamento que flutua entre a mobilidade e a imobilidade, dado tanto pelos aspectos formais desse cinema quanto pela construção dos personagens e do reconhecimento de seus contextos sócio-geográficos. É preciso entender, nesse sentido, a repetição e a imobilidade incorporadas como operações dessa lentidão menos radical e, ao mesmo tempo, como processos letárgicos de permanência das contradições da paisagem estadunidense.

Esses processos, que se apresentam materialmente na forma fílmica e nos percursos dos corpos pelo espaço fílmico, estabelecem aquilo que Reichardt se refere como um "transe de caminhada". A manifestação de um caminho, seja a partir das operações continuadas de trabalho na paisagem ou pelo reconhecimento de um processo histórico de habitações que se constituíram ali, vai ser estabelecida e restabelecida em diversas obras, textos e imagens da paisagem estadunidense, como o texto de Silko ou o próprio cinema de Reichardt - que contrapõem uma imagem da conquista, a imagem de uma única habitação possível, com a apresentação de uma diversidade de habitações e de um pertencimento fragmentado, incerto e diverso. Mas, em Reichardt, esse caminho se estabelece e restabelece, continuadamente, por sobre essa imagem do país como fronteira, uma expressão que designa não apenas um espaço geográfico, mas a natureza do movimento em direção a ele, identificado como progresso e iniciativa valorosa. É essa imagem também que tanto $O$ atalho quanto Wendy e Lucy, como a narrativa de uma mulher que atravessa o país em busca de emprego e oportunidade, percorrem quando lidam com as contradições entre as promessas feitas e as paisagens atravessadas em busca delas. Essas contradições são produzidas em uma manutenção dessas promessas, que se dá inclusive pela permanência da expressão fronteira para identificar o país, uma expressão que continua a ser enfatizada por todo o século XX, como nos mostra Patricia Nelson Limerick (1994): da abertura da série Jornada nas estrelas ${ }^{15}$ até os discursos de presidentes como Franklin Roosevelt, John F. Kennedy e, repetida e reiteradamente, Ronald Reagan. É nessa impossibilidade de chegar à prometida fronteira que

\footnotetext{
${ }^{15} \mathrm{Na}$ abertura da série vemos a espaçonave Enterprise, que os personagens habitam, cruzando o espaço, enquanto a voz de William Shatner como Capitão Kirk proclama: "Space, the final frontier. These are the voyages of the starship Enterprise, its five year mission to seek out new life and new civilizations. To boldly go where no man has gone before".
} 
se produz a imobilidade e letargia do movimento dos personagens - é nela que se produz o road movie fracassado de Reichardt.

O espaço de $O$ atalho contradiz essa noção de fronteira - um termo "criticado por seu etnocentrismo e sua imprecisão" (Limerick 1994, 72) como representativo do processo colonial estadunidense e da "complexa História de encontros culturais na colonização" (Limerick 1994, 79) e um termo, também, muito presente no imaginário do faroeste, gênero fílmico e literário que se refere, geralmente, à expansão histórica da colonização estadunidense para o Oeste $^{16}$. É pela ideia da fronteira que operou esse primeiro processo imperialista do país - um país que, nos diz David Harvey (2003), não gosta de pensar em si mesmo como um império. Quando $O$ atalho é produzido, no entanto, a vinculação do país a um "novo imperialismo" (Harvey 2003) já estava mais do que evidente. O governo de Bush Jr. e a chamada "guerra ao terror" apresentaram "um reconhecimento público do império e do imperialismo" e a "admissão de algo que se sucedia há algum tempo" (Harvey 2003, 25). Ao voltar à ideia de fronteira no contexto do imperialismo contemporâneo, é esse tipo de reconhecimento que Kelly Reichardt coloca em operação.

Aqui, uma romantização da fronteira como o espaço em que processos culturais dinâmicos - e até cosmopolitas - estão em ação dá lugar a uma imagem de precariedade e despossessão da fronteira, do campo e da pequena cidade estadunidenses. A temporalidade de Reichardt nos traz à presença dessa precariedade ao incorporar materialmente os padrões de movimento dos corpos que circulam pelo espaço representado. Quando vemos, nos créditos de abertura de Wendy e Lucy, diversos planos de um trem de carga que se move devagar e para aos poucos - criando um procedimento dialético com a lentidão e imobilidade da própria protagonista, que aparece para nós logo após esse material de carga e parte, enfim, junto com ele -, somos postos diante da materialidade austera dos procedimentos econômicos daquela comunidade. Na fronteira de $O$ atalho, o que é posto em cena são os processos de trabalho incorporado: alimentar o gado, cozinhar, lavar, coletar, inicialmente, quando há água; caminhar, quando não há. Os filmes de Reichardt estão sempre partindo, em suas sequências de abertura, desse padrão de movimento de uma comunidade, apresentado como um procedimento de duração particular: o conjunto de operações de trabalho dos colonos junto ao rio, em $O$ atalho; e a carga que para sobre os trilhos ao fim do dia, em Wendy and Lucy.

\footnotetext{
16 É importante fazer uma ressalva, nesse sentido, em favor do que Stephen Aron observa no texto "The making of the first American west and the unmaking of other realms", em que afirma ser "impossível entender a criação das terras ao oeste [...] tratando-as apenas por Oeste" $(2004,5)$. Diz o autor: "Então, como agora, o Oeste não era oeste para muitas das pessoas que lá viviam ou que para lá se moveram. No século XVIII, essas terras ao oeste, grande parte da América do Norte, na verdade, eram o destino para movimentos populacionais de várias direções (Aron 2004, 5).
} 
Fusco e Seymour (2017) percebem com desconfiança uma romantização da lentidão no cinema em uma atitude da crítica ${ }^{17}$. Para as autoras (2017), tal caracterização "falha em compreender que a lentidão pode na verdade ser um problema, e um problema da modernidade contemporânea". Fusco e Seymour (2017, 54) se referem a uma "modernidade experimentada como lentidão" por aqueles que são marginalizados - e em detrimento deles - e, citando Rob Nixon (2011 apud Fusco e Seymour 2017, 54), também a "uma violência lenta", de uma destruição dispersa e atrasada. Essa noção de uma violência lenta e de sua ação na paisagem (Nixon, afinal, é um autor da ecocrítica e está se referindo aí também a procedimentos de destruição de caráter ecológicos) nos tira a imagem de uma fronteira da conquista e da ocupação idealizadas e apresenta uma outra imagem estabelecida dos limites do país, mas uma já reconhecida por sua história de conflitos, violência e despossessão - a frontera, paisagem ao Norte do México e ao Sul dos EUA, o saliente de turquesas de Silko. Investigando a permanência do uso da ideia de fronteira nos EUA do século XX, Patricia Nelson Limerick descobre, na frontera, uma oposição desestabilizadora, pois não há, nessa outra imagem, "nenhuma ilusão de espaço vazio, conclusões triunfais ou simplicidade" (Limerick 1994, 90).

Enquanto a fronteira sugere, problematicamente, um movimento positivo e dinâmico, a frontera produz uma imagem mais próxima desse processo histórico de lentidão e violência, como experimentadas por personagens despossuídos, habitantes (desabitados) dessa paisagem. Para Fusco e Seymour (2017, 55), o caráter de lentidão permite perceber o que "se poderia, de outro modo, deixar de ver - não para apreciá-las, mas para questionar que forças encorajaram esse negligenciamento em primeiro lugar; e para registrar a invisibilidade e a invisibilização tanto quanto o invisível". Essa operação, reconhecida no cinema de Reichardt, engaja-se em um outro procedimento de registro da paisagem e daqueles que a ocupam, um que se distancia do faroeste tradicional e se aproxima não apenas da frontera posta em cena por autores como Leslie Marmon Silko (uma paisagem permanentemente em tensão com a História, memória e a ideia de pertencimento ao país), mas também das paisagens de lentidão, violência e despossessão que se apresentam fora da sensação estadunidense de lugar, como as paisagens argentinas de Lisandro Alonso, a paisagem brasiliense de Adirley Queirós e demais paisagens contemporâneas como apresentas por diretores como Lav Diaz, Tsai Ming-Liang, Hou Hsiao-Hsien, Apichatpong Weerasethakul, Chantal Akerman, Claire Denis, entre outras e outros.

O movimento hesitante e lento levado adiante por corpos perdidos, desabrigados, forçados a dar voltas sem destino certo, em Reichardt, torna-se uma oportunidade para o reconhecimento da precariedade da frontera, de uma política de austeridade posta aos limites geográficos e socioeconômicos do país, um espaço produzido

\footnotetext{
${ }^{17}$ São citados pelas autoras textos de Edward Guthmann, A. O. Scott e Harry Tuttle, especificamente, em que esses críticos exaltam uma qualidade da lentidão que os leva à meditação, contemplação e um chamado a ir mais devagar.
} 
tanto a partir das frustradas iniciativas de conquista quanto pela austeridade econômica que resulta dessas iniciativas. O processo de habitação que é representado em $O$ atalho, marcado pela não conquista e incerteza, continua em Wendy e Lucy, como uma continuidade da crise.

Em Wendy e Lucy, quando a protagonista se aproxima de um grupo de pessoas acampando, desabitadas, nas proximidades da cidade, Reichardt nos coloca diante de uma construção histórica da despossessão. Wendy ainda tem seu carro, sua Lucy e fortes esperanças de chegar ao Alasca, onde buscará o emprego. Ao conversar com Icky (Will Oldham), uma dessas figuras desabitadas, que está voltando do Alasca em direção ao Sul (de onde Wendy veio), a personagem é confrontada com a possibilidade de que o Alasca talvez não lhe ofereça a solução para o contexto de precariedade em que se encontra e de que, possivelmente, tão logo ela deva fazer o mesmo percurso de volta ao Sul, sem nunca conseguir se desvincular da austeridade dessa paisagem entre os destinos, entre esperanças.

Descrevendo uma apresentação da fadiga em Wendy and Lucy - e também no filme Rosetta (1999) -, Elena Gorfinkel (2012, 324) coloca como a expressão do cansaço nesses filmes "se torna o princípio de um conjunto de potenciais agonísticos - de possibilidade e impossibilidade políticas, de atividade e inatividade, de movimento e inércia, de discurso e silêncio". O percurso de Wendy pela cidade de onde ela não consegue sair e, mais do que isso, por uma paisagem de precariedade - o percurso de um corpo cansado, como Gorfinkel enfatiza -, é um que coloca em operação esses potenciais agonísticos.

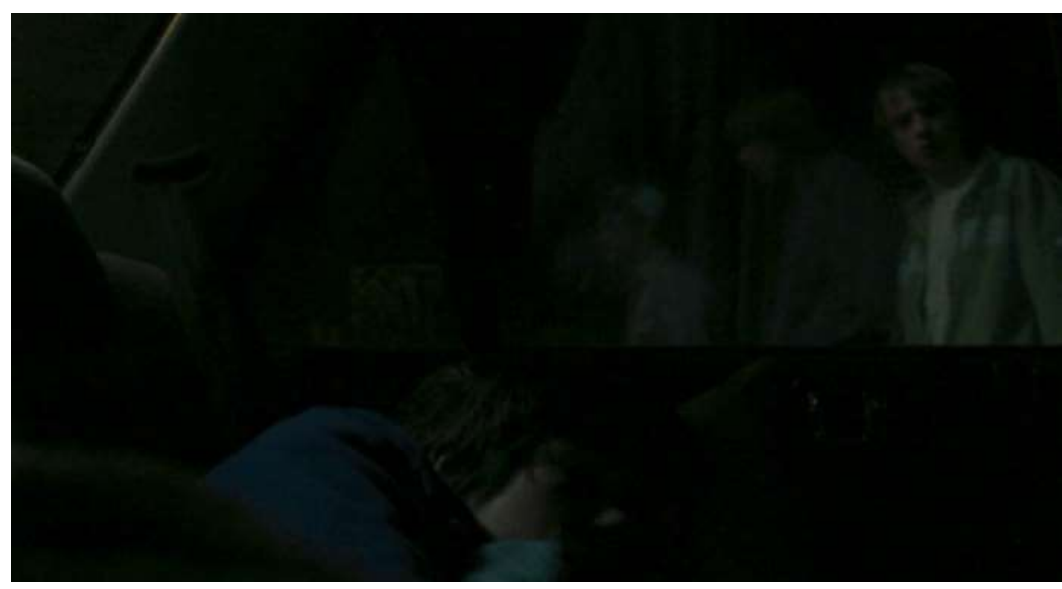

Figura 4: Cena do filme Wendy e Lucy (2008) | (c) Film Science, Washington Square Films et al.

Como em $O$ atalho, em que o quadro mais fechado imita a visão das personagens femininas, que, com seus grandes chapéus, não podem ver muito além do que está a sua frente, a fotografia em Wendy e Lucy também se limita a apresentar o que está ao alcance da experiência da personagem. Desse modo, o corpo cansado de Wendy também determina a maneira como percebemos aquele espaço. A 
paisagem do Oregon se torna um produto muito direto da fadiga de uma desabitada, de um corpo cada vez mais marginalizado, ainda mais quando a austeridade desse espaço se apresenta formalmente por uma radical aproximação à visão da personagem, como quando a protagonista é eventualmente confrontada com a materialidade da escuridão nas cenas em que Wendy tenta dormir, mas tem seu sono perturbado por corpos masculinos que a interpelam, intimidam e assediam. Em Wendy and Lucy, o percurso que segue a promessa americana de fartura - aquela que Wendy ainda procura ver cumprida - sequer permite um movimento da sua protagonista, restrita à imobilidade e à inércia. Esse espaço dos EUA, então, a pequena cidade do país, a fronteira onde uma nova habitação se vislumbra, revela-se em uma precariedade materializada nos caminhos sem rumo, nas cargas de trem que não são levadas para lugar nenhum, na vulnerabilidade vivida na escuridão e no corpo exausto dessa personagem, intimidado e incapaz de reagir.

\section{Considerações finais}

A materialidade dos EUA de Kelly Reichardt é a de um reconhecimento histórico de um processo lento e disperso de violência e despossessão. É a materialidade da frontera, como descrita por Limerick (1994), desestabilizando a imagem da fronteira. É a materialidade, também, do trajeto desses corpos. Gorfinkel (2012), afinal, compara os filmes Wendy e Lucy e Rosetta não pelas especificidades geográficas e históricas que esses filmes trazem adiante, mas por um reconhecimento da encenação dos corpos: corpos de mulheres, de trabalhadores, corpos cansados e à deriva, corpos que habitam uma experiência de precariedade. A materialidade da frontera é também, como podemos concluir voltando a Grosz (1992), a materialidade de uma subjetivação do espaço no corpo e a inscrição desse corpo no espaço. Além disso, se partimos do princípio, como fazemos, de que esse "espaço" é subjetivizado no corpo, então reconhecemos que esse corpo que se encena no espaço midiático é necessariamente um corpo agenciado por especificidades históricas e geográficas, além de, evidentemente, por como essas especificidades constroem relações de gênero, classe, raça $\mathrm{e}$ nacionalidade e por como essas relações definem modos de habitação e pertencimento no espaço. Isso, ainda mais, é algo que pode ser dito de qualquer corpo, ou seja, de qualquer materialidade extramidiática que é agenciada midiaticamente.

É preciso problematizar o conceito de paisagem para tensionar a distinção entre corpo e espaço na representação fílmica. Dizer que há uma incorporação do espaço no movimento dos personagens, ou que a paisagem estadunidense é descrita por tais movimentos, é reconhecer que corpo e espaço são ambos assimilados a uma mesma materialidade fílmica. O cinema de Reichardt se apresenta como um objeto de estudo de particular interesse, nesse sentido, no que sua materialidade fílmica, que poderia ser referida também como uma materialidade de movimento (corporificada pela decupagem, 
montagem, design de som, etc.), vincula-se aos processos de tarefagem que formam aquele espaço como paisagem. E esta se torna, necessariamente, uma vinculação dos filmes à historicidade dessa paisagem, a seu reconhecimento social e geográfico. Dificilmente essa vinculação se materializaria no atalho a que o título de um dos filmes, de tal modo ironicamente, se refere, mas sim na caminhada como uma atividade laboriosa. Caminhada, trabalho, habitação e desabitação são materializados por Reichardt em sua forma fílmica, em um quadro do país e descrição da paisagem, do mesmo modo que, em sua travessia, Silko materializa, de um reconhecimento histórico das habitações, o seu saliente de turquesa.

\section{BIBLIOGRAFIA}

Aron, Stephen. 2004. "The making of the first American west and the unmaking of other realms". Em A companion to the American west, editado por William Deverell, 5-24. Oxford: Blackwell.

Butler, Judith, e Athena Athanasiou. 2013. Dispossession: the performative in the political. Cambridge: Polity Press.

Careri, Francesco. 2013. Walkscapes: o caminhar como prática estética. São Paulo: G. Gili.

Certeau, Michel de. 1998. A invenção do cotidiano. Petrópolis: Editora Vozes.

Dillard, Clayton. 2016. "Interview: Kelly Reichardt on Certain Women and the politics of anger". Acesso em: 09 de junho de 2019. https://www.slantmagazine.com/features/article/interviewkelly-reichardt-on-certain-women-and-the-politics-of-anger.

Fusco, Katherine, e Nicole Seymour. 2017. Kelly Reichardt. Urbana: University of Illinois Press.

Gilbey, Ryan. 2011. "Kelly Reichardt: how I trekked across Oregon for Meek's Cutoff then returned to teaching”. Acesso em: 09 de junho de 2019. https://www.theguardian.com/film/2011/apr/09/kellyreichardt-meeks-cutoff.

Gorfinkel, Elena. 2016. "Exhausted drift: austerity, dispossession and the politics of slow in Kelly Reichardt's Meek's Cutoff”. Em Slow cinema, editado por Tiago de Luca e Nuno Barradas Jorge, 123-136. Edinburgh: Edinburgh University Press.

----. 2012 "Weariness, waiting: enduration and art cinema's tired bodies". $\quad$ Discourse $34 \quad$ (2-3): 311-347. https://muse.jhu.edu/article/522516.

Grosz, Elizabeth. 1992. "Bodies-cities”. Em Sexuality \& Space, editado por Beatriz Colomina, 241-254. Nova York: Princeton Architectural Press.

Harvey, David. 2003. El nuevo imperialismo. Madrid: Akal. 
Ingold, Tim. 2015. Estar vivo: ensaios sobre movimentação, conhecimento e descriçãa. Petrópolis: Vozes.

----. 1993. “The temporality of the landscape”. World Archaeology 25 (2): 151-174. doi: 10.1080/00438243.1993.9980235.

Lefebvre, Martin. 2006. Landscape and film. Nova York: Routledge.

Levitt, Jeremy I., e Matthew C. Whitaker. 2009. Hurricane Katrina: America's unnatural disaster. Lincoln: University of Nebraska Press.

Limerick, Patricia Nelson. 1994. "The adventures of the frontier in the twentieth century". Em The frontier in American culture, editado por James R. Grossman, 67-102. Berkeley: University of California Press.

Longworth, Karina. 2011. "Kelly Reichardt explains "Meek's Cutoff", her latest road movie". Acesso em: 09 de junho de 2019. https://archives.sfweekly.com/sanfrancisco/kelly-reichardtexplains-meeks-cutoff-her-latest-roadmovie/Content?oid=2181363.

Luca, Tiago de, e Nuno Barradas Jorge. 2016. Slow cinema. Edinburgh: Edinburgh University Press, 2016.

Marx, Leo. 2000. The machine in the garden: technology and the pastoral ideal in America. Nova York: Oxford University Press.

Nancy, Jean-Luc. 2005. The ground of image. Nova York: Fordham University Press.

Quijano, Aníbal. 2005. "Colonialidade do poder, Eurocentrismo e América Latina”. Em A colonialidade do saber: eurocentrismo e ciências sociais, organizado por Edgardo Lander, 117-142. Buenos Aires: CLACSO.

Schafer, R. Murray. 1994. Our sonic environment and the soundscape: the tuning of the world. Rochester: Destiny Books.

Silko, Leslie Marmon. 2010. The turquoise ledge. [E-book]. Nova York: Penguin.

\section{FILMOGRAFIA}

Meek's Cutoff [longa-metragem, arquivo digital] Dir. Kelly Reichardt. Evenstar Films et al., EUA, 2010. 102 min.

Old Joy [longa-metragem, arquivo digital]. Dir. Kelly Reichardt. Film Science et al., EUA, 2006. $76 \mathrm{~min}$.

Wendy and Lucy [longa-metragem, arquivo digital]. Dir. Kelly Reichardt. Film Guide Films et al., EUA, 2008. 80 min. 